\title{
MEMAKNAI PERAN ALKITAB DALAM PERTUMBUHAN ROHANI MAHASISWA KRISTEN MELALUI PEMURIDAN KONTEKSTUAL DI SURAKARTA (Sebuah Interpretative Phenomenological Analysis)
}

\author{
Efi Nurwindayani \\ STT Gamaliel Surakarta \\ windayani.efi@gmail.com
}

\begin{abstract}
Abstrak
The focus of this research is "Interpreting the Role of the Bible in the Spiritual Growth of Christian Students through Contextual Discipleship in Surakarta." This study aims to find the meaning of the role of the Bible in the spiritual growth of Christian students through Contextual Discipleship in Surakarta. This study used a qualitative research design with a phenomenological approach to the Interpretative Phenomenological Analysis model. Through this research, the writer found the meaning of the Bible's very important role in the spiritual growth of students. Students are aware of many challenges that keep them from growing spiritually. But with the awareness that the Bible is the revelation of God without error and without defects, it is what encourages students to strive to be faithful in studying it so that spiritual growth is continually renewed into mature, Christ-like individuals.
\end{abstract}

Keywords: Interpretation, Role, Bible, Spiritual Growth, Students, Discipleship

\begin{abstract}
Abstrak
Fokus penelitian ini adalah "Memaknai Peran Alkitab Dalam Pertumbuhan Rohani Mahasiswa Kristen Melalui Pemuridan Kontekstual Di Surakarta." Penelitian ini bertujuan untuk menemukan makna tentang peran Alkitab dalam pertumbuhan rohani mahasiswa Kristen melalui Pemuridan Kontekstual di Surakarta. Penelitian ini menggunakan rancangan penelitian kualitatif dengan pendekatan fenomenologis model Interpretative Phenomenological Analysis. Melalui penelitian ini penulis menemukan makna peran Alkitab yang sangat penting dalam pertumbuhan rohani mahasiswa. Mahasiswa menyadari banyak tantangan yang membuatnya tidak bertumbuh rohaninya. Tetapi dengan kesadaran Alkitab adalah wahyu Allah tanpa salah dan tanpa cacat itulah yang mendorong mahasiswa berjuang tetap setia mempelajarinya sehingga terciptalah pertumbuhan rohani yang terus diperbaharui menjadi pribadi yang dewasa serupa Kristus.
\end{abstract}

Kata Kunci: Memaknai, Peran, Alkitab, Pertumbuhan Rohani, Mahasiswa, Pemuridan

\section{Pendahuluan}

Rasul Paulus menegaskan Alkitab adalah tulisan yang diilhamkan Allah. Alkitab memiliki peran yang sangat penting bagi kehidupan orang percaya yaitu mengajar, menyatakan kesalahan, memperbaiki kelakuan dan mendidik orang dalam kebenaran Kegiatan-kegiatan tersebut (khususnya mengajar dan mendidik) dapat dilakukan dengan berbagai metode (Santosa, 2014). 
Donald G. Bloesch, penulis buku yang berjudul Christian Foundations, Holy Scripture, Revelation, Inspiration And Ilmumination mengatakan: saya sangat percaya bahwa Alkitab dapat menjadi panduan yang otoritatif (norma tertinggi) dan kredibel untuk iman dan praktik hidup pada masa sekarang ini. ${ }^{1}$ Pada saat Alkitab menjadi panduan dan norma tertinggi maka kehidupan orang percaya ada dalam pertumbuhan rohani yang mantap.

Pertumbuhan rohani harus terjadi dalam kehidupan setiap orang percaya, termasuk mahasiswa Kristen yang sedang menempuh pendidikan di perguruan tinggi. Mahasiswa pada hakekatnya adalah kaum intelektual yang sedang dalam persoalan dan pencarian arti hidup yang sebenarnya. Mereka membutuhkan pedoman agar memiliki kehidupan yang taat dalam kebenaran Firman Tuhan. $^{2}$ Pertumbuhan rohani mahasiswa memiliki sarana petumbuhan baik secara pribadi maupun bersama dalam konteks tubuh Kristus.

Salah satu sarana pertumbuhan rohani mahasiswa dalam konteks tubuh Kristus di Surakarta adalah melalui Pemuridan Kontekstual dalam bentuk Kelompok Tumbuh Bersama Kontekstual. Kelompok pemuridan ini bertujuan agar setiap anggotanya, yaitu

\footnotetext{
${ }^{1}$ Donald G. Bloesch, Christian Foundations, Holy Scripture, Revelation, Inspiration And Ilmumination, (British Ubrary Qltaloguing-inPublication Data, 2008), 15
}

mahasiswa Kristen di kampus menjadi pribadi yang bertumbuh rohaninya serupa Kristus melalui pembelajaran Alkitab secara kontinyu dan konsisten.

$$
\text { Rasul Paulus menegaskan }
$$

pertumbuhan rohani adalah suatu pembaharuan hidup menjadi pribadi yang serupa Kristus. Keserupaan dengan Kristus meliputi aspek-aspek hidup baik karakter, kognitif, kehendak, komitmen, relasi, skill dan ketrampilan. Kedewasaan inilah yang diupayakan melalui pembelajaran Alkitab dalam konteks tubuh Kristus, yaitu melalui Pemuridan Kontekstual.

Pelaksanaan pemuridan kontekstual mahasiswa di Surakarta belum berjalan secara tetap dan terus menerus. Banyak mahasiswa yang diawal pemuridan bersemangat belajar Firman Tuhan, namun berhenti di tengah jalan. Berdasarkan pengamatan penulis dan wawancara awal dengan beberapa pemimpin pemuridan, salah satu faktor penyebabnya adalah mahasiswa kurang mengenal Alkitab dan perannya bagi pertumbuhan rohani. Mahasiswa memang tahu Alkitab, namun belum sampai pada pemaknaan yang benar akan perannya sebagai pedoman hidup yang berotoritas sehingga perlu dipelajari bersama dengan tekun dan setia. Jika mahasiswa mengenal Alkitab dan perannya yang sangat

\footnotetext{
${ }^{2}$ Harianto GP, Mission For City, (Bandung: Penerbit Agiamedia, 2006), 153
} 
penting bagi pertumbuhan imannya, niscaya mahasiswa akan bertumbuh rohaninya. Pertumbuhan rohani selalu mencakup pengertian, penghargaan, penerimaan dan menikmati anugerah Allah. ${ }^{3}$

Berdasarkan penjelasan tersebut diatas, dapat ditarik suatu perumusan masalah yaitu: Bagaimana Memaknai Peran Alkitab Bagi Pertumbuhan Rohani Mahasiswa Kristen Melalui Pemuridan Kontekstual Di Surakarta? Tujuan dari penulisan ini adalah untuk menemukan makna tentang peran Alkitab dalam pertumbuhan rohani mahasiswa Kristen melalui Pemuridan Kontekstual di Surakarta. Manfaat dari tulisan ini adalah, pertama secara teoritis dapat menemukan makna tentang peran Alkitab bagi pertumbuhan rohani mahasiswa Kristen melalui Pemuridan Kontekstual di Surakarta. Kedua, secara praktika, memberikan semangat dan motivasi kepada mahasiswa Kristen di Surakarta agar tekun, setia, dan taat mempelajari Firman Tuhan melalui kelompok Pemuridan Kontekstual secara kontinyu dan konsisten. Dampaknya tentu jelas, yaitu adanya pertumbuhan rohani dalam kedewasaan penuh serupa Kristus.

\section{Metode Penelitian}

\footnotetext{
${ }^{3}$ Sinclair B. Ferguson, Bertumbuh Dalam Anugerah, (Surabaya: Penerbit Moentum, 2002), 58

${ }^{4}$ Sugiyono, Metode Penelitian Kuantitatif, Kualitatif dan $R \& D$, (Bandung: Penerbit Alfabeta, 2015), 8
}

Penelitian ini menggunakan rancangan penelitian kualitatif dengan pendekatan fenomenologis. Penelitian kualitatif sering disebut juga penelitian naturalistik adalah penelitiaan yang dilakukan pada kondisi yang alamiah (natural). Filsafat yang mendasarinya adalah postpositivisme (paradigm interpretif dan konstruktif) yang memandang realita sosial sebagai sesuatu yang holistik (utuh), kompleks, dinamis, penuh makna dan hubungan gejala yang bersifat interaktif. Penelitian kualititatif dilakukan pada obyek yang alamiah, artinya obyek yang berkembang apa adanya, tidak dimanipulasi oleh kehadiran peneliti dan kehadiran peneliti tidak mempengaruhi dinamika pada obyek tersebut. ${ }^{4}$ Penelitian ini menggunakan pendekatan fenomelogi. Fenomenologi berasal dari kata fenomena yang berarti kejadian mental, peristiwa mental, aktivitas mental yang dialami partisipan atau subyek penelitian. Fenomena adalah bagian dari pengalaman hidup partisipan. Jadi penelitian fenomenologi adalah penelitian tentang pengalaman subyektif. Peneliti mengambil versi pendekatan fenomenologi interpretatif (Interpretaitive Phenomenological Analysis) dimana peneliti ingin menafsirkan bagaimana setiap partisipan memberi arti untuk setiap pengalamannya. $^{5}$

\footnotetext{
${ }^{5}$ YF La Kahija, Penelitian Fenomenologis. Jalan Memahami Pengalaman Hidup, (Yogyakarta: Penerbit Kanisius, 2017), 20, 25
} 
Sumber data dalam penelitian ini adalah tiga mahasiwa Kristen yang ada di Surakarta, yang memiliki pengalaman sebagai anggota kelompok pemuridan yaitu Kelompok Tumbuh Bersama Kontekstual (KTBK).

Penelitian fenomenologis berupaya untuk memperoleh apa yang ada di balik penggambaran orang mengenai pengalamannya, yaitu sampai pada struktur yang mendasari kesadaran. Untuk itu, cara penelitian yang dilakukan penulis adalah dengan wawancara atau percakapan panjang sebagai sumber data. ${ }^{6}$

\section{Hasil dan Pembahasan}

A. Mengenal Alkitab dan Perannya Bagi Kehidupan Orang Percaya

Pada dasarnya manusia memiliki hasrat untuk mengenal penciptanya dan memiliki persekutuan yang erat dengan-Nya. ${ }^{7}$ Tetapi karena keberdosaannya maka manusia terbatas dalam mengenal Allah. Yesaya 59: 1-2 mencatat sesungguhnya yang membuat keterbatasan tersebut adalah dosa. Yesaya mengatakan yang merupakan pemisah antara kamu dan Allahmu ialah kejahatanmu. Dan yang membuat Ia menyem-bunyikan diri adalah segala dosamu.

${ }^{6}$ Andreas B. Subagyo, Pengantar Riset Kuantitatif dan Kualitatif. Termasuk Riset Teologi dan Keagamaan, (Bandung: Kalam Hidup, 2001), 112

${ }^{7}$ W. Gary Crampton, Verbum Dei (Alkitab: Firman Allah), (Surabaya: Penerbit Momentum, 2000), 20
Bloesch menulis: that real knowledge of God is not possible apart from faith, which is a gift of the Spirit of God. We do not mount up to the supernatural on a ladder of speculation (as in medieval scholasticism), but Christ descends to us, confronting us in our despair and need as the Savior of the world. Nature does not lead to grace; instead grace recasts and transforms natur. ${ }^{8}$ Pendapat Bloesch ini menegaskan bahwa pengenalan akan Allah tidak dapat dilepaskan dari iman dan hal ini adalah anugerah Allah. Manusia tidak mungkin naik mengenal yang supra natural, justru sebaliknya, Allah dalam Kristus Yesus yang turun kepada manusia supaya manusia mengenal Allah.

Tindakan Allah untuk memperkenalkan diri-Nya kepada manusia dengan tujuan agar manusia mengenal Allah disebut dengan pewahyuan (revelation) yang dalam bahasa Yunani menggunakan istilah apokalupsis yang artinya penyingkapan atau dibukakan. Ada dua jenis wahyu Allah, yaitu wahyu umum dan wahyu khusus. ${ }^{9}$ Wahyu umum menyatakan dimana Allah menyatakan kebenaran-kebenaran tertentu dan aspek-aspek tentang naturnya kepada semua umat manusia. Ruang lingkup wahyu ini mencakup seluruh dunia. Sedangkan wahyu khusus fokusnya

${ }^{8}$ Donald G. Bloesch, Christian Foundation. Holy Scripture: Revelation, Inspiration And Intepretation,

${ }^{9}$ W. Gary Crampton, Verbum Dei (Alkitab: Firman Allah), 25 
lebih sempit dari wahyu umum dan terbatas pada Yesus Kristus dan Kitab Suci. Wahyu khusus dibutuhkan karena keadaan manusia yang berdosa. Dalam rangka pemulihan persekutuan manusia dengan Allah, maka diperlukan wahyu khusus yang berpusat pada pribadi Yesus Kristus. ${ }^{10}$

Alkitab sebagai wahyu khusus dari Allah disampaikan kepada penulis yang memiliki latar belakang berbeda-beda. Pada saat penulis Alkitab menuliskan wahyu Allah ada proses yang disebut dengan inspirasi (inspiration). Definisi inspirasi adalah pimpinan Roh Kudus pada para penulis Alkitab, sehingga meskipun penulisan dilakukan sesuai dengan gaya dan kepribadian mereka, hasilnya adalah Firman Allah yang tertulis, yang berotoritas, patut dipercaya dan bebas dari salah dalam autograph yang asli. ${ }^{11}$ Inspirasi Alkitab bersifat verbal artinya kata demi kata diilhamkan Allah, bukan dengan dikte, tetapi melalui pimpinan atau penjagaan Roh Kudus kepada para nabi atau penulis Alkitab dengan tetap memakai kosakata dan gaya penulisan para nabi itu sendiri dan plenary artinya tidak ada bagian dalam Alkitab yang tidak diilhamkan Allah. Karena Alkitab adalah wahyu Allah, dan Allah benar tidak salah, maka Alkitab juga benar dan tidak salah.

\footnotetext{
${ }^{10}$ Paul Enns, The Moody Handbook Of Theology, (Malang: Literatur SAAT, 2012), 189-192

${ }^{11}$ Paul Enns, The Moody Handbook Of Theology, 193
}

Ketaksalahan Alkitab adalah doktrin Alkitab yang sangat penting dan perlu diketahui setiap orang percaya. Dalam istilah teologi, ketaksalahan Alkitab disebut dengan istilah ineransi (inerrancy). Ineransi menurut kamus oxford berarti kualitas atau kondisi dari keberadaan yang tanpa salah; bebas dari kesalahan. Istilah ineransi ini hanya dihubungkan dengan naskah asli Alkitab (original authographs). Kata yang bersinonim dengan istilah ineransi adalah infalibel (infallible), artinya Alkitab tidak dapat keliru. ${ }^{12}$

Alkitab yang ineran dan infalibel berotoritas bagi hidup orang percaya. Istilah otoritas berasal dari bahasa Yunani yaitu exousia yang berarti kuasa yang adil, sungguh, tak terhalangi bertindak, atau memiliki, mengontrol, memakai atau menguasai sesuatu atau seseorang. Selain itu dapat diartikan kuasa yang bagaimanapun adalah sah. Exousia dapat menekankan keabsahan otoritas yang dipegang. ${ }^{13}$

Otoritas Alkitab itulah yang membuat Alkitab berperan penting dalam kehidupan orang percaya. Di Perjanjian Lama, salah satu nats yang menjelaskan tentang peran Alkitab (Firman Tuhan) ditulis oleh pemazmur dalam mazmur 119: 9-16. Pemazmur menuliskan betapa pentingnya Firman Tuhan bagi seorang

\footnotetext{
${ }^{12}$ Arnold Tindas, Apakah Inerrancy Alkitab Itu?, (Manado: Sinode Masehi Protestan Umum, 1993), 5-7

${ }^{13}$ STT Gamaliel Surakarta, Bahan Ajar Mata
} Kuliah Bibliologi. 
muda yaitu berperan dalam mempertahankan kelakuan bersih, tidak menyimpang dari kebenaran, menjaga hidup dari dosa dan menjadikan hidup sukacita (bergembira). Seorang muda harus mencari Firman Tuhan dengan segenap hati, menyimpan janji Firman Tuhan itu dalam hati, membuka hati untuk diajar Firman Tuhan, merenungkannya dengan sungguh-sungguh dan bergemar dalam Firman-Nya.

Di Perjanjian Baru, Paulus dalam surat penggembalaannya di 2 Timotius 3: 15-17 menuliskan peran penting Kitab Suci bagi kehidupan Timotius. Kebenaran Kitab Suci menolong dalam memberi hikmat dan menuntun pada keselamatan oleh iman dalam Yesus Kristus. Selain itu, Kitab Suci berperan dalam mengajar, menyatakan kesalahan, untuk memperbaiki kelakuan dan mendidik orang dalam kebenaran. Dengan demikian Timotius dan setiap orang percaya diperlengkapi Kitab Suci untuk setiap perbuatan baik.

\section{B. Pertumbuhan Rohani Mahasiswa}

Tidak ada pertumbuhan rohani tanpa belajar Firman Tuhan. Injil Yohanes mencatat perkataan Tuhan Yesus: jikalau kamu tetap dalam Firman-Ku, kamu benar-benar adalah murid-Ku. Seorang murid artinya seorang pelajar. Kata pelajar berasal dari akar kata yang bermakna "pikiran disertai dengan

${ }^{14}$ J. Oswald Sanders, Spiritual Discipleship (Kemuridan Rohani), (Batam: Gospel Press, 2002), 3334 upaya". Jadi seorang murid Kristus adalah seorang pelajar, yang mempelajari pengajaran tuannya (Yesus) bukan hanya dalam kepercayaan melainkan juga dalam gaya hidupnya. Menjadi murid Kristus berarti juga menerima pandangan-pandangan dan praktikpraktik sang Guru serta taat pada perintahperintah-Nya. $^{14}$

Seorang murid Kristus yang melakukan pembelajaran Firman Tuhan melalui proses pemuridan akan membawa transformasi spiritual bagi kehidupannya. Proses pemuridan mentransformasi bukan hanya pikiran dan emosi melainkan juga aspek kehendak. ${ }^{15}$ Paulus dalam suratnya kepada Jemaat Efesus di Kitab Efesus 4: 13-16 mengatakan, pertumbuhan rohani dalam konteks tubuh Kristus membawa orang percaya memiliki pengetahuan yang benar tentang anak Allah, kedewasaan penuh dan tingkat pertumbuhan yang sesuai dengan kepenuhan Kristus. Kondisi ini akan membawa orang percaya tidak mudah diombang-ambingkan oleh rupa-rupa angin pengajaran dan tetap teguh berpegang kepada kebenaran dan terus bertumbuh dalam segala hal ke arah Kristus yang adalah kepala jemaat.

Keserupaan dengan Kristus sebagai goal dalam pertumbuhan rohani orang percaya meliputi beberapa aspek, yaitu rohani, pikiran, sikap, karakter, perilaku, relasi, kehendak dan

${ }^{15}$ David Platt, Follow Me, (Surabaya: Literatur Perkantas, 2017), 156 
pelayanan yang semuanya mencerminkan teladan Kristus atau sama seperti Kristus. ${ }^{16}$

\section{Pemuridan Kontekstual}

Panggilan orang percaya yang sudah diselamatkan oleh Yesus Kristus adalah menjadi murid Kristus. Seorang murid Kristus harus selalu belajar Alkitab. Melalui pemuridan kontekstual, seorang percaya akan ditolong belajar Firman Tuhan sehingga mengalami pertumbuhan iman. Pemuridan Kontekstual adalah suatu proses memuridkan setiap orang percaya yang berpusatkan Kristus, berdasarkan Firman Allah dan melalui kuasa Roh Kudus agar menjadi dewasa serupa Kristus. Proses ini berlangsung seumur hidup, dimulai sejak menerima Yesus sebagai Tuhan dan Juruselamat. ${ }^{17}$

Ada banyak model Pemuridan, salah satunya adalah Kelompok Tumbuh Bersama Kontekstual - KTBK (Contextual Bible Group). KTBK adalah sekelompok orang yang didiami Roh Kristus, berjumlah 3-6 orang yang rindu dan komitmen mempelajari Firman Tuhan dengan benar, menaati Firman Tuhan, memiliki relasi persahabatan dengan pemimpin dan anggota lainnya, mengontrol dan melipatgandakan KTBK Baru. ${ }^{18}$

\footnotetext{
${ }^{16}$ Persekutuan Mahasiswa Kristen Surakarta, Bahan Training Pemuridan Kontekstual Mahasiswa

${ }^{17}$ Bahan Kuliah Pemuridan Kontekstual, STT Gamaliel Surakarta

${ }^{18}$ Bahan Training Pelayanan Mahasiswa, Persekutuan Mahasiswa Kristen Surakarta.

${ }^{19}$ Metode induktif kontekstual adalah sebuah metode belajar Alkitab yang menekankan "eksegese"
}

Visi KTBK adalah murid Kristus akan terus bertumbuh sampai kedewasaan penuh kearah Kristus melalui pembelajaran Firman Tuhan di dalam persekutuan tubuh Kritsus. Ada lima misi KTBK yaitu: mendorong peserta bertumbuh dewasa serupa Kristus, melengkapi peserta dengan pemahanan Alkitab secara induktif kontekstual ${ }^{19}$, mengontrol peserta taat Firman Tuhan, dan mendelegasi anggota menjadi pemimpin KTBK baru. ${ }^{20}$

\section{Pelaksanaan KTB Kontekstual} meneladani kehidupan persekutuan jemaat mula-mula yang tertulis dalam Kitab Kisah Para. Pertama, belajar Firman Allah (learning) secara induktif-kontekstual. Kedua, penyembahan dan doa (worship). Penyembahan merupakan respon seseorang untuk memuji dan membesarkan Nama Tuhan. Ketiga, persekutuan (fellowship). Persekutuan kasih yang terjadi di antara anggota KTBK akan menyaksikan kepada orang lain bahwa mereka benar-benar murid Kristus. Keempat, pengutusan (mission). KTBK terkait erat dengan pengutusan. Pengutusan adalah kesaksian anggota KTBK untuk pergi memberitakan Injil dan membentuk KTBK baru.

yaitu menarik keluar setiap prinsip Firman Tuhan, ditafsirkan menurut konteks dan maksud penulis Alkitab dan mengaplikasikannya dalam konteks masa kini. Metode induktif kontekstual mencoba menarik pesan asli Alkitab.

${ }^{20}$ Timotius Haryono, Pemuridan Kontekstual, (Surakarta: Yayasan Gamaliel, 2018), 60 
Materi yang digunakan dalam pemuridan di KTB Kontekstual adalah Seri Buku KTBK berdasarkan Kitab Suci yang dirancang menurut tiga skope pertumbuhan yaitu peneguhan (bagi para petobat baru), pembinaan dasar (orang percaya yang sedang bertumbuh rohaninya) dan pembinaan lanjut (orang percaya yang sudah terlibat aktif dalam pelayanan). Metode belajar Alkitab yang dipergunakan adalah metode induktif kontekstual. Metode ini berusaha mencari pesan asli dari Alkitab, menafsirkannya dan menerapkannya dalam konteks hidup masa kini. Metode induktif kontekstual menggunakan tiga langkah belajar Firman Tuhan, yaitu observasi, intepretasi dan aplikasi.

\section{Hasil: Memaknai Peran Alkitab Bagi Pertumbuhan Rohani Mahasiswa Melalui Pemuridan Kontekstual}

Alkitab adalah Firman Allah yang ineran dan infallible dan menjadi pedoman hidup orang percaya. Alkitab berperan penting bagi pertumbuhan rohani setiap orang percaya termasuk mahasiswa. Kesadaran peran Alkitab ini yang menyebabkan mahasiswa tetap setia mempelajarinya ditengah tantangan studi dan pergaulan mereka.

\section{Partisipan DJ}

DJ adalah seorang mahasiswi angkatan tahun 2017. DJ berasal dari luar jawa dan tinggal di sebuah kost mahasiswa di Surakarta. Saat ini DJ sedang menempuh kuliah di tingkat akhir pembelajaran di Fakultas MIPA, Program Studi Matematika Universitas Sebelas Maret Surakarta. DJ mengalami kelahiran baru pada saat mengikuti sebuah acara kebaktian kebangunan rohani di Persekutuan Mahasiswa Kristen. Setelah menerima Kristus, DJ mengalami perubahan hidup yang fundamental terkait relasinya dengan Firman Tuhan. Hatinya haus untuk mengenal kehendak Allah melalui FirmanNya. Dan mulailah ia mendalami Alkitab baik secara pribadi melalui kehidupan saat teduh dan secara kelompok dalam pemuridan kontekstual melalui wadah atau bentuk Kelompok Tumbuh Bersama Kontekstual (KTBK) dari sejak lahir baru sampai saat ini.

Motivasi yang mendorongnya untuk menjadi murid Kristus yang setia dan tekun belajar Alkitab adalah keyakinannya akan Alkitab adalah Firman Allah. Firman Allah adalah wahyu Allah yang tertulis. Firman Allah tidak pernah salah. Firman Allah inilah yang memiliki kuasa untuk mengubah kehidupannya menjadi pribadi yang lebih baik dari hari ke sehari. Firman Tuhan adalah pedoman dalam hidup terkhusus dalam menghadapi situasi sulit dalam hidup ini.

Transformasi kehidupan yang dialami DJ dirasakan dalam beberapa aspek hidup. Pertama, pengetahuan yaitu semakin mengenal Kristus dan karakter-Nya. DJ mengakui bahwa 
setelah ikut pemuridan KTB Kontekstual, menjadi lebih memahami secara mendalam kebenaran Alkitab. Kedua, karakter yaitu perubahan watak. Dulu sebelum mengenal Kristus, mengabaikan cintanya terhadap Alkitab. Alkitab hanya dibaca seminggu sekali pada saat ibadah di gereja. Tetapi sekarang, karena cintanya kepada Firman Tuhan, setiap hari merenungkan Firman Tuhan dan secara periodik menyediakan waktu menyelidiki Alkitab melalui pemuridan kontekstual. Ketiga, perilaku yaitu kehidupan yang taat pada Firman Tuhan. Salah satu bentuk ketaatannya adalah memenuhi panggilan pelayanan sebagai pembuat murid, yaitu menjadi pemimpin Kelompok Tumbuh Bersama Kontekstual. DJ mengakui bahwa pertumbuhan rohaninya juga merupakan karya Roh Kudus.

Tantangan yang dihadapi DJ dalam mengejar pertumbuhan rohani melalui pembelajaran Alkitab dalam pemuridan kontekstual adalah kesibukan dalam jam kuliah dan mengerjakan deadline tugas kuliah. Ditengah kepadatan aktifitasnya, DJ tetap berjuang menyediakan waktu seminggu sekali untuk belajar Firman Tuhan dalam kelompok pemuridan KTB Kontekstual.

\section{Partisipan AS}

AS adalah mahasiswa semester lima di sebuah fakultas keguruan dan ilmu pendidikan di sebuah kampus di Surakarta. Sejak kecil orang tuanya sudah memberinya Alkitab. Namun demikian ia jarang membaca dan merenungkannya. Pada waktu remaja, AS mulai belajar Firman Tuhan dalam kelompok pendalaman Alkitab di gerejanya. Namun hal ini tidak dilakukannya secara rutin dan kontinyu. Hingga akhirnya setelah lulus SMA, AS diterima kuliah dan mengalami peneguhan lahir baru dan berkomitmen untuk sungguhsungguh hidup bagi Tuhan.

Perubahan hidup setelah lahir baru dalam kaitannya dengan Alkitab terasa sangat besar. Sebelum lahir baru, Alkitab memang ia miliki, namun menganggapnya kurang penting dan berperan dalam hidup ini. Alkitab jarang dibaca. Namun setelah lahir baru, kesadaran bahwa Alkitab itu penting dan berperan dalam pertumbuhan iman mulai tumbuh. Kesadaran ini memberi dorongan yang sangat kuat untuk berkomitmen merenungkan Firman Tuhan secara pribadi. Selain itu, mulai mempelajarinya melalui kelompok pemuridan di kampus yaitu dalam KTB Kontekstual.

Keyakinan bahwa Alkitab adalah Firman Allah yaitu tulisan yang diilhamkan Allah memberi semangat dan motivasi bagi Arian untuk mempelajarinya dalam melalui KTB Kontekstual. Peran Alkitab begitu penting yaitu menjadi dasar pertumbuhan rohani dan aturan dalam bertindak atau perilaku. Sebagai mahasiswa, ada banyak godaan yang berpotensi menyimpangkan hidupnya dari kebenaran, dan Firman Tuhan 
lah yang menolongnya untuk tetap bertahan dalam hidup yang kudus dan suci.

Ada perasaan sukacita, senang saat belajar Firman Tuhan melalui pemuridan kontekstual di KTB Kontekstual. Bahkan pengenalannya akan kebenaran Firman Tuhan makin ditambahkan dan diperkaya. AS juga mengakui bahwa jika hidupnya tanpa belajar Firman Tuhan maka pastilah akan kacau, tanpa tujuan, tanpa pengharapan dan dapat jatuh dalam dosa. Oleh karena itu AS terus berupaya di tengah tantangan yang ada berusaha selalu menyediakan waktu untuk belajar Firman Tuhan melalui kelompok pemuridan KTBK di kampus.

Pertumbuhan rohani yang dirasakan dari Firman Tuhan adalan pengenalannya akan Allah makin kuat dan ini berdampak dalam sikap hidupnya, pola pikirnya dan pola bicaranya. Demikian juga saat memilih keputusan, AS selalu berpedoman dengan kebenaran Alkitab. Selain menjadi anggota KTBK, AS juga mulai belajar melayani sebagai pemimpin KTBK yang juga membimbing adik-adik tingkat di fakultas yang sama untuk belajar Firman Tuhan juga. Semangat untuk memuridkan bertumbuh seiring pertumbuhan rohaninya dalam Firman Tuhan.

AS mengatakan bahwa tantangan terbesar seorang muda dalam belajar Firman Tuhan adalah sikap cuek atau apatis atau masa bodoh terhadap hal-hal yang bersifat rohani.
Hal ini sangat mungkin terjadi mengingat mahasiswa banyak mengerjakan tugas sehingga, waktu yang ada banyak dialihkan untuk mengerjakan tugas kuliah dan mengabaikan pertumbuhan rohaninya.

\section{Partisipan SR}

SR adalah seorang mahasiswi semester 5 yang saat ini menempuh pendidikan di prodi farmasi, sebuah kampus swasta di Surakarta. SR berasal dari Sumba dan tinggal di sebuah kos yang berdekatan dengan kampus tempat ia menempuh pendidikan. Sejak kecil SR sudah dididik oleh kedua orang tuanya untuk mengenal Alkitab. Kedua orang tuanya taat beribadah dan mengenal Tuhan dengan baik, dan memberikannya Alkitab sejak kecil.

SR sudah bertobat dan lahir baru pada saat SMA. Setelah menjadi mahasiswa, SR melalui perkuliahan kelas Pendidikan Agama Kristen mendapat materi tentang pemuridan kontekstual KTB Kontekstual termotivasi untuk belajar Alkitab secara kontinyu. Tetapi bukan hanya karena ikut kelas agama saja ia termotivasi bertumbuh dalam iman, melainkan juga karena keyakinannya bahwa Alkitab mengajarkan kebenaran. Keyakinan bahwa Alkitab benar, tidak mungkin salah, memotivasinya untuk mendalaminya.

Pertumbuhan rohani menurut SR adalah suatu kondisi terkait dengan relasinya dengan Tuhan yaitu dekat dengan Allah melalui Firman-Nya sehingga mengalami 
perubahan hidup dari manusia lama menjadi manusia baru yang menjadi lebih baik. SR mengakui bahwa sebelum bertobat, rohaninya tidak mengalami pertumbuhan. Kurang serius dan fokus dalam mengupayakan pertumbuhan rohani. Sibuk dengan hidupnya dan tanpa memikirkan imannya. Namun, setelah mengenal Kristus, SR mengandalkan Tuhan dengan cara bertekun dalam pembelajaran Firman Tuhan.

SR mengikuti pemuridan kontekstual melalui KTBK di Persekutuan Mahasiswa Kristen Surakarta. SR mengakui bahwa ber KTBK membuatnya lebih mengenal Allah melalui firman-Nya. Selain itu juga memiliki relasi dengan saudara seiman dalam lingkup yang lebih luas. Sebagai orang yang merantau jauh dari keluarga, kebutuhannya untuk dikuatkan dan diarahkan ia dapatkan melalui kelompok pemuridan KTB Kontekstual. SR sangat tertarik dan terkesan ikut pemuridan KTBK. Bahkan diantara teman-teman se kampusnya, hanya SR yang masih terus bertahan belajar Firman Tuhan sampai sekarang ini.

Alasan SR tetap bertahan dan termotivasi belajar Firman Tuhan adalah kesadarannya bahwa tanpa belajar Firman Tuhan hidup menjadi tanpa arah, tanpa tujuan, banyak masalah dan terlebih lagi pertumbuhan rohani menjadi terhambat. Diakuinya ada banyak tugas kuliah dan praktikum di kampus. Selain itu, lingkungan pergaulan yang bebas menjadi faktor yang membuat mahasiswa tidak serius memperhatikan pertumbuhan imannya. SR tetap berupaya belajar Firman Tuhan melalui pemuridan kontekstual di KTBK.

Salah satu buah pertumbuhan rohani, SR terlibat dalam pelayanan sebagai pengurus Persekutuan Mahasiswa Kristen Surakarta sebagai koordinator doa mahasiswa di Surakarta. Hidup yang bertumbuh menyerupai Yesus salah satunya adalah terlibat dalam pelayanan sama seperti Kristus juga melayani manusia dengan sukacita.

\section{Penutup}

Alkitab adalah wahyu Allah yang tertulis, tanpa salah dan tanpa cacat. Karena itulah Alkitab berotoritas dan menjadi pedoman hidup yang berperan penting dalam menolong perumbuhan rohani setiap orang percaya termasuk mahasiswa Kristen. Goal pertumbuhan rohani adalah hidup yang serupa dengan Kristus yang meliputi yaitu aspek rohani, pikiran, sikap, karakter, perilaku, relasi, kehendak dan pelayanan.

Salah satu sarana pertumbuhan rohani mahasiswa Kristen adalah melalui Pemuridan Kontekstual dalam bentuk Kelompok Tumbuh Bersama Kontekstual (KTBK). Melalui KTBK, mahasiswa Kristen ditolong untuk mengerti dan memahami Alkitab dengan metode induktif kontekstual yaitu observasi, intepretasi dan aplikasi. KTBK beranggotakan 
3-6 orang yang berkomitmen tekun dan konsisten belajar Alkitab minimal seminggu sekali bertemu bersama.

Berdasarkan wawancara dengan tiga partisipan, peneliti menemukan makna peran penting Alkitab bagi pertumbuhan rohani mahasiswa. Jika disingkat, maka peran penting Alkitab ada 4M. Pertama, Alkitab Membawa transformasi (perubahan) hidup mahasiswa Kristen. Alkitab membuat mahasiswa memiliki fokus hidup yang benar yaitu mengenal Allah. Kerinduan, kehausan dan kecintaan akan Allah mendorong mahasiswa komitmen sungguh-sungguh menyediakan waktu ditengah padatnya jam kuliah dan deadline tugas-tugas kuliah. Kedua, Alkitab Menguatkan hidup mahasiswa. Ditengah kebingungan, pergumulan mahasiswa dan pilihan-pilihan etis konteks mahasiswa, Alkitab menjadi pedoman hidup yang membuat mahasiswa tetap kuat dan mengambil pilihan yang benar. Ketiga, Alkitab Memberi semangat melayani dan kaderisasi pemimpin baru. Mereka yang sudah mengenal Alkitab termotivasi mengajak mahasiswa lainnya juga mengenal Alkitab. Mahasiswa berkomitmen menjadi pemimpin-pemimpin pemuridan bagi sesama mahasiswa di kampusnya masing-masing. Dan M yang ke empat adalah Alkitab Memberi sukacita hidup. Sukacita hidup adlah kebutuhan psikologis bagi orang percaya. Sukacita sejati didapat dari relasi dengan Kitab Suci. Benar kata pemazmur, bahwa peringatan-peringatanNya menjadi petunjuk yang mendatangkan sukacita (Mazmur 119: 14).

Saran dari penelitian ini adalah pertama, perlunya seminar tentang doktrin Alkitab (bibliologi) konteks mahasiswa yang bertujuan membukakan wawasan mahasiswa akan pengajaran Alkitab yang benar. Dengan demikian mahasiswa yang selama ini enggan bertumbuh dan belajar Firman Tuhan menjadi termotivasi untuk ikut pemuridan kontekstual khususnya dalam bentuk KTBK. Kedua, perlunya penelitian lanjutan yang bertujuan mengukur efektivitas Pemuridan Kontektual KTBK sehingga didapatkan data secara kuantitatif. Hal ini akan melengkapi tulisan ini sehingga ada masukan secara mendetail mengenai efektifitas pelayanan pemuridan kontekstual melalui KTB Kontekstual di mahasiswa.

\section{Referensi}

Bahan Kuliah Pemuridan Kontekstual, STT Gamaliel Surakarta

Bahan Training Pelayanan Mahasiswa, Persekutuan Mahasiswa Kristen Surakarta.

Bloesch, Donald G. Christian Foundations, Holy Scripture, Revelation, Inspiration And Ilmumination. British Ubrary Qltaloguing-in-Publication Data, 2008)

Crampton, W. Gary. Verbum Dei (Alkitab: Firman Allah). Surabaya: Penerbit Momentum, 2000 
Enns, Paul. The Moody Handbook Of

Theology. Malang: Literatur SAAT, 2012

Ferguson, Sinclair B. Bertumbuh Dalam Anugerah. Surabaya: Penerbit Moentum, 2002

GP, Harianto. Mission For City. Bandung: Penerbit Agiamedia, 2006

Haryono, Timotius, Pemuridan Kontekstual.

Surakarta: Yayasan Gamaliel, 2019

La Kahija, YF. Penelitian Fenomenologis. Jalan Memahami Pengalaman Hidup. Yogyakarta: Penerbit Kanisius, 2017

Persekutuan Mahasiswa Kristen Surakarta, Bahan Training Pemuridan Kontekstual Mahasiswa

Platt, David. Follow Me. Surabaya: Literatur Perkantas, 2017
Sanders, J. Oswald. Spiritual Discipleship (Kemuridan Rohani). Batam: Gospel Press, 2002

Santosa, D. S. S. Pengaruh Budaya Belajar, Strategi Pengajaran Dosen, dan Motivasi Belajar Terhadap Hasil Belajar Mahasiswa Pendidikan Ekonomi FKIP UKSW/ Journal of Educational Social Studies. Vol . 3 (2), 2014

STT Gamaliel Surakarta, Bahan Ajar Mata Kuliah Bibliologi.

Subagyo, Andreas B. Pengantar Riset Kuantitatif dan Kualitatif. Termasuk Riset Teologi dan Keagamaan. Bandung: Kalam Hidup, 2001

Sugiyono. Metode Penelitian Kuantitatif, Kualitatif dan $R \& D$. Bandung: Penerbit Alfabeta, 2015

Tindas, Arnold. Apakah Inerrancy Alkitab Itu? Manado: Sinode Masehi Protestan Umum, 1993 